\title{
Modeling the Bullying Prevention Program Preferences of Educators: A Discrete Choice Conjoint Experiment
}

\author{
Charles E. Cunningham • Tracy Vaillancourt • \\ Heather Rimas • Ken Deal • Lesley Cunningham • \\ Kathy Short • Yvonne Chen
}

(C) Springer Science + Business Media, LLC 2009

\begin{abstract}
We used discrete choice conjoint analysis to model the bullying prevention program preferences of educators. Using themes from computerized decision support lab focus groups ( $n=45$ educators), we composed

Dr. Cunningham is Professor, Department of Psychiatry and Behavioural Neurosciences, and the Jack Laidlaw Chair in PatientCentred Health Care. Dr. Vaillancourt is Associate Professor, Canada Research Chair, Faculty of Education and School of Psychology. Dr. Deal is Associate Professor of Strategic Market Leadership and Health Services Management. This project was supported by a Community University Research Alliance Grant form the Social Sciences and Humanities Research Council of Canada and the Jack Laidlaw Chair in Patient-Centred Health at McMaster University Faculty of Health Sciences. The authors would like to express their appreciation to the school boards and educators that supported this project and for the editorial assistance provided by Donna Bohaychuk, Stephanie Mielko, and Jenna Ratcliff. Address correspondence to Charles E.

Cunningham, McMaster Children's Hospital, Hamilton, Ontario,

Canada, L8P 1B3. Electronic mail may be sent via Internet to cunnic@hhsc.ca
\end{abstract}

C. E. Cunningham $(\square)$

Offord Centre for Child Studies,

McMaster Children's Hospital, McMaster University,

Hamilton, ON, Canada L8P 1B3

e-mail: cunnic@hhsc.ca

T. Vaillancourt

University of Ottawa,

Ottawa, Canada

T. Vaillancourt

Offord Centre for Child Studies, McMaster University,

Hamilton, Canada

H. Rimas $\cdot$ K. Deal $\cdot$ Y. Chen

McMaster University,

Hamilton, Canada

L. Cunningham $\cdot$ K. Short

Hamilton-Wentworth District School Board,

Hamilton, Canada
20 three-level bullying prevention program design attributes. Each of 1,176 educators completed 25 choice tasks presenting experimentally varied combinations of the study's attribute levels. Latent class analysis yielded three segments with different preferences. Decision Sensitive educators (31\%) preferred that individual schools select bullying prevention programs. In contrast, Support Sensitive educators $(51 \%)$ preferred that local school boards chose bullying prevention programs. This segment preferred more logistical and social support at every stage of the adoption, training, implementation, and long term maintenance processes. Cost Sensitive educators (16\%) showed a stronger preference for programs minimizing costs, training, and implementation time demands. They felt prevention programs were less effective and that the time and space in the curriculum for bullying prevention was less adequate. They were less likely to believe that bullying prevention was their responsibility and more likely to agree that prevention was the responsibility of parents. All segments preferred programs supported by the anecdotal reports of colleagues from other schools rather than those based on scientific evidence. To ensure that the bullying prevention options available reflect the complex combination of attributes influencing real world adoption decisions, program developers need to accommodate the differing views of the Decision, Support, and Cost Sensitive segments while maximizing the support of parents and students.

Keywords Bullying · Prevention · Conjoint analysis . Preferences $\cdot$ School

Bullying is associated with significant developmental risks for both perpetrators and victims (Arseneault et al. 2006; Kim et al. 2006). Survey research and observational studies 
suggest that a considerable percentage of the bullying children participate in, or are the victims of, occurs at school (Olweus 1994). Although promising bullying prevention programs are available (Fekkes et al. 2006; Frey et al. 2005; Mytton et al. 2006; Vreeman and Carroll 2007), schools often fail to adopt those with the strongest evidence base (Fagan and Mihalic 2003). When evidence-based prevention programs are adopted, they may not be implemented with the fidelity needed to ensure their success (Kallestad 2003; Payne et al. 2006), nor sustained long enough to yield a significant impact (Fekkes et al. 2006).

The adoption and implementation of school-based prevention programs is best understood via multi-level models (Shinn 2003) reflecting the complex interplay between characteristics of the program, the dissemination process, individuals within the organization (Kallestad 2003), the school adopting the program (Gregory et al. 2007), and the broader educational and community systems in which schools function (Elias et al. 2003; Lochman 2003; Ringeisen et al. 2003). Research on the diffusion of innovations suggests that the adoption of prevention programs will be influenced by the perceived severity and importance of the problem (Kallestad 2003), the relative advantage of a new approach, the program's compatibility with the adopting organization's needs, beliefs, and values, the program's level of complexity, the extent to which the program can be piloted, and the degree to which a program's impact can be observed (Greenhalgh et al. 2004; Rogers 2003). Individual level models, such as the Theory of Planned Behavior (TPB), suggest that the adoption of bullying prevention programs would be influenced by expectations regarding a program's effectiveness (Attitudes), social pressures (Subjective Norms), and beliefs regarding one's ability to conduct the program successfully (Perceived Behavioral Control) (Armitage and Conner 2001; Perkins et al. 2007).

Because teachers exert considerable influence on the adoption of bullying prevention programs (Kallestad 2003), developers must work closely with the educators who ultimately implement these programs (Greenberg 2004; Hoagwood and Johnson 2003; Ringeisen et al. 2003; Spoth et al. 2004). Given limitations in time and resources, educators face difficult choices between competing educational responsibilities and prevention program demands (Greenberg et al. 2003; Ringeisen et al. 2003). Program developers, in turn, are confronted with complex design tradeoffs. Understanding the relative importance of different design attributes to educators may help developers incorporate features that increase adoption, limit modifications that reduce effectiveness (Cunningham et al. 1998; Payne et al. 2006; Rones and Hoagwood 2000), and support the long-term maintenance needed to achieve meaningful outcomes (Greenberg 2004; Spoth et al. 2004).

\section{The Current Study}

We used a discrete choice conjoint experiment to study factors influencing the decision of educators to adopt bullying prevention programs. Choice-based conjoint methods conceptualize a product or service as a series of multi-level attributes (Orme 2006). A bullying prevention program's attributes, for example, might include training costs, implementation time demands, and supporting evidence. Participants choose between options composed of experimentally varied attribute combinations (Orme 2006). Choice tasks prompt participants to evaluate each attribute in the context of others and to weigh the tradeoffs associated with competing design alternatives. Because complex choices limit superficial decisions, activate the heuristics influencing real world decisions (Shah and Oppenheimer 2008), and reduce social desirability biases (Caruso et al. 2009; Phillips et al. 2002), these methods provide better estimates of actual behavior (Ryan et al. 2001). Finally, as decompositional approaches, conjoint methods can simulate preferences for existing programs, predict responses to innovative program attribute combinations, predict the extent to which preferred attributes compensate for critical features with low utility, and estimate the relative influence of the attributes composing complex options (Orme 2006).

Conjoint methods were developed by mathematical psychologists (Luce and Tukey 1964) and are widely used by transportation economists (Hensher et al. 2005), health economists (Ryan et al. 2007), and marketing researchers (Gustafsson et al. 2007). These methods have been extended to study the information preferences of parents of children with mental health problems (Cunningham et al. 2008) and to inform the design of prevention programs for parents (Spoth and Redmond 1993). Cunningham et al. (2008), for example, studied the information preferences of 1,192 parents seeking children's mental health services. Segmentation analysis yielded an Action segment preferring materials providing step-by-step solutions to their child's difficulties, an Information segment preferring materials helping parents understand their child's problems, and an Overwhelmed segment that avoided information. The current study is, to our knowledge, the first application of these methods to the design of school-based prevention programs.

This study addressed three questions. First we postulated that the relative importance of different bullying prevention program design attributes would vary. To explore this, we computed importance scores reflecting the sensitivity of participants to variations in the levels of each bullying prevention program attribute and computed utility values ${ }^{1}$

\footnotetext{
${ }^{1}$ Sometimes referred to by market researchers as part-worth utility values (Orme 2006)
} 
reflecting the influence of each attribute's levels on program choices. Second, given diversity in educational settings (Elias et al. 2003), we assumed that there would be differences in the bullying prevention program design preferences of individual educators. To address this question, we conducted latent class analyses identifying segments with different bullying prevention program preferences. We compared the importance scores and utilities of each segment, and explored the correlates of segment membership. Finally, to understand the response of different segments of educators to complex bullying prevention design options, we computed simulations predicting the bullying prevention program design choices of each segment.

\section{Method}

\section{Discrete Choice Conjoint Survey Participants}

Between January 2006 and January 2008, we recruited the study's 1,176 participants. The public and Catholic school boards serving a community of 505,000 residents identified 22 representative schools. Two schools elected not to participate. Of the 450 educators eligible to participate, 314 (70\%) completed surveys. In addition, each board posted a survey link to the e-mail addresses of all educators in their system. An additional 862 participants returned surveys. We discontinued recruiting when the total sample $(N=1,176)$ was adequate for latent class segmentation analysis (Orme 2006). This project received ethical clearance from each school board and the University's Research Ethics Board.

\section{Survey Development}

Attribute selection is a critical step in the design of conjoint analytic studies (Hensher et al. 2005). Because theoretical models or a priori assumptions might exclude attributes influencing consumer choices, qualitative methods are widely used to ensure that the full range of attributes of interest to consumers is considered in the survey design process (Coast 1999; Orme 2006). Qualitative data can also inform the wording of attributes, the range of attribute levels, and the interpretation of findings (Coast 1999). In the attribute development stage of this study, therefore, we recruited a purposeful sample of educators $(n=45)$ from the public and Catholic school boards participating in this study. The sample included senior administrators $(n=4)$, principals $(n=8)$, vice principals $(n=6)$, teachers $(n=13)$, school social workers $(n=9)$, and consultants $(n=5)$. An experienced facilitator conducted two 3-hour focus groups in a Decision Support Lab equipped with 25 computer terminals allowing participants to simultaneously enter comments. Anonymous entries and voting results were projected at the front of the lab. Following consent procedures, demographic questions, and a warm-up task, participants listed factors that would lead them to adopt or reject bullying prevention programs, clustered entries into themes, and voted on the ten most important themes. Participants then listed and voted on specific examples representing each theme. A detailed presentation of these findings is the focus of a separate paper.

Using focus group themes, we composed 20 bullying prevention attributes. To avoid a bias when attributes with differing numbers of levels are included in the same study (Orme 2006), we defined each attribute by four levels. Although mathematical efficiency increases as a function of the number of attributes presented in each choice task, informant efficiency declines (Patterson and Chrzan 2004). To balance informant and statistical efficiency (Patterson and Chrzan 2004), each of 25 choice tasks presented three optional bullying prevention programs, each described by the levels of two attributes (Fig. 1). Each survey included one example and two identical hold-out tasks to determine the percentage of participants who responded consistently when presented with the same choice (96.4\%). We used data from 22 choice tasks to determine the validity of our simulations by predicting hold-out task responses (Orme 2006). To maximize efficiency, Sawtooth Software's experimental design module composed 1,005 unique survey attribute combinations using principles of minimal overlap, level balance, and orthogonality (Orme 2006). We e-mailed a survey link to educators with internet access $(n=1,040)$ and provided a paper version when internet access was unavailable $(n=136)$.

\section{Dependent Measures}

Participants responded to 5-point Likert scale questions (scored $1=$ Strongly Disagree to $5=$ Strongly Agree)
Fig. 1 A sample of the format used in the 25 choice tasks completed by each participant. Note that Sawtooth Software's experimental design module composed surveys with different survey attribute combinations
If these were your only options, click on the anti-bullying program you would prefer:
Program 1

Staff spend 1 day

learning to implement the program

The program is promising but unproven
Program 2

Staff spend 3 days learning to implement the program

Scientific studies (e.g. randomized trials) say the program reduces bullying
Program 3 Staff spend 2 days learning to implement the program

Staff from other schools say the program reduced bullying

$$
\text { ○ }
$$

o 
composing the following subscales from the Bullying Prevention Attitudes Scale (Cunningham et al. 2009). This measure was developed in the context of this study to reflect constructs from models of individual (Perkins et al. 2007) and organizational change (Cunningham et al. 2002) which might be associated with differences in bullying prevention program preferences.

Severity of the Bullying Problem This 3-item scale (Cronbach's $\alpha=0.91)$ measured the extent to which educators believed that bullying was a serious problem in their school(s) (e.g., Too many students at this school are bullied by other children).

Perceived Efficacy of Bullying Prevention This 3-item scale (Cronbach's $\alpha=0.93$ ) measured the extent to which educators believed that bullying prevention programs were effective (e.g., Anti-bullying programs reduce the number of children who are bullied).

Barriers to Bullying Program Implementation This 3-item scale (Cronbach's $\alpha=0.70$ ) measured the extent to which time and curriculum requirements prevented participation in anti-bullying programs (e.g., I don't have enough time to help with anti-bullying programs).

Stakeholder Support This 3-item scale (Cronbach's $\alpha=$ 0.81) measured whether participants felt that parents, colleagues, and administrators would support their prevention efforts (e.g., Administrators would support me if I tried to develop anti-bullying programs).

Decision Control This 3-item scale (Cronbach's $\alpha=0.87$ ) measured the extent to which educators felt they had the opportunity to influence the development of bullying prevention programs in their schools (e.g., I can influence how bullying is dealt with in this school).

Intent to Implement Bullying Prevention This 3-item scale (Cronbach's $\alpha=0.87$ ) measured the extent to which educators were ready to participate in the implementation of bullying prevention programs (e.g., I am willing to help our school reduce bullying).

Staff Morale This 3-item scale (Cronbach's $\alpha=0.86$ ) measured morale among staff (e.g., The morale of staff in this school is high).

Student Morale This 3-item scale (Cronbach's $\alpha=0.87$ ) measured the extent to which the school's atmosphere was positive for students (e.g., Students enjoy being in this school).
Locus of Responsibility Individual questions addressing the extent to which participants believed the prevention of bullying was the responsibility of themselves, the school, or parents.

Demographic Characteristics Participants reported basic demographic characteristics, their years of experience as educators, the divisions in which they worked, their role within the school, and their experience with prevention programs.

\section{Data Analysis}

We adopted an approach to data analysis widely used by marketing researchers (Orme 2006). We used hierarchical Bayesian methods (CBC/HB 3.1) to compute utility coefficients for each participant (Allenby et al. 1995; Lenk et al. 1996; Sawtooth Software Inc. 2004a). This program uses Bayes theorem and simulated Monte Carlo Markov Chain processes (e.g. Gibbs Sampling) to estimate conjoint utilities. The hierarchical Bayesian algorithm samples from two distributions: (1) an upper level model which estimates part-worth utility averages and variances for the sample population, and (2) a lower level model drawing on the choices of each respondent in the study sample. We standardized (zero-centered) utilities setting the average utility value range of all attributes to 100 (Orme 2006). Utility values reflect the relative influence of each attribute level on participant choices with higher values indicating stronger preferences. To estimate the relative influence of each attribute, we computed importance scores by converting each attribute's utility value range to a percentage of the sum of the utility value ranges of all attributes (Orme 2006). Variations in the levels of attributes with higher importance scores exert more influence on participant choices (Orme 2006).

Sawtooth Software's Latent Class (Version 3) module was used to identify segments with similar prevention preferences (DeSarbo et al. 1995; Orme 2006; Sawtooth Software 2004b; Ramaswamy and Cohen 2007). Latent Class computes the probability of membership in each segment and yields solutions with a better fit than cluster or aggregate analyses (DeSarbo et al. 1995; Orme 2006; Vriens et al. 1996). We replicated the latent class solution five times beginning at random starting points, assuming convergence when log-likelihood decreased by less than 0.01 , and accepting an interpretable solution with the best fit (Chi Square). We used Chi Square and ANOVAs to compare the demographic characteristics of segments and one-way between-segment MANOVAs across Bullying Prevention Attitudes Scale scores, importance scores, and utility values. When MANOVAs were statistically significant, Brown-Forsythe ANOVAs (Gamage and Weerahandi 1998) and post hoc Dunnett's C tests were used to compare the means for each segment. 
Table 1 Demographics of the Decision Sensitive, Support Sensitive, and Cost Sensitive Segments

\footnotetext{
${ }^{1} 1=1$ year or less, $4=11-$

15 years, $7=$ more than 25 years

$*_{p}<0.05$

$* * p<0.01$

$* * * p<0.001$
}

\begin{tabular}{|c|c|c|c|c|c|c|}
\hline \multirow[t]{2}{*}{ Measure } & \multirow[t]{2}{*}{$N$} & \multirow[t]{2}{*}{$n$} & \multicolumn{3}{|l|}{ Segment } & \multirow[t]{2}{*}{$F$ or $X^{2}$} \\
\hline & & & Decision & Support & Cost & \\
\hline Sample Size & 1,176 & & 406 & 599 & 170 & \\
\hline Experience $^{1}$ & 1,175 & & 4.3 & 4.3 & 4.2 & 0.8 \\
\hline Sex & 1,173 & & & & & 5.5 \\
\hline$\%$ Men & & 295 & 30.8 & 50.8 & 18.3 & \\
\hline$\%$ Women & & 878 & 35.8 & 51.0 & 13.2 & \\
\hline Divisions Worked In & 1,174 & & & & & \\
\hline \% Preschool & & $292^{`}$ & 31.5 & 56.5 & 12.0 & 5.1 \\
\hline \% Primary/Junior & & 800 & 34.0 & 52.4 & 13.6 & 2.5 \\
\hline$\%$ Intermediate & & 458 & 36.0 & 50.7 & 13.3 & 1.2 \\
\hline$\%$ Secondary Schools & & 272 & 32.4 & 52.2 & 15.4 & 0.8 \\
\hline Role in the School & 1,175 & & & & & $22.0 * *$ \\
\hline$\%$ Administrators & & 148 & 27.0 & 64.2 & 8.8 & \\
\hline$\%$ Teaching Staff & & 824 & 37.7 & 47.1 & 15.2 & \\
\hline \% Educational Assistants & & 124 & 26.6 & 55.6 & 17.7 & \\
\hline$\%$ Support Staff & & 78 & 28.2 & 59.0 & 12.8 & \\
\hline Participated in Prevention Program & 1,174 & & & & & 4.0 \\
\hline$\%$ Yes & & 810 & 35.2 & 51.7 & 13.1 & \\
\hline$\%$ No & & 365 & 33.2 & 49.3 & 17.5 & \\
\hline Number of Programs Participated in & 1,174 & & 1.6 & 1.6 & 1.3 & 1.9 \\
\hline
\end{tabular}

Finally, we used randomized first choice simulations (Sawtooth Software CBC SMRT V.4.7.3) to predict responses to the study's two hold-out tasks and to model each segment's response to five hypothetical bullying prevention programs (Orme 2006). Simulations begin with a maximum utility rule assuming that participants choose programs with the highest composite utility and improve share of preference predictions by estimating attribute and program variability (Huber et al. 2007).

\section{Results}

Segmentation Analysis Latent class analysis yielded three segments with $31 \%$ of the participants in a Decision Sensitive segment, $51 \%$ in a Support Sensitive segment, and $16 \%$ in a Cost Sensitive segment. Although a greater proportion of administrators (64.2\%) and support staff (59.0\%) were members of the Support Sensitive segment, the segments did not differ on the basis of sex, school
Table 2 Bulling Prevention Attitudes Scale Scores for the Decision Sensitive, Support Sensitive, and Cost Sensitive Segments

${ }^{1} 1$ = Strongly Disagree, $5=$ Strongly Agree

${ }^{2}$ Brown-Forsythe $\mathrm{F}$

${ }^{3}$ Dunnett's C

${ }^{*} p<0.05$

$* * p<0.01$

$* * * p<0.001$

\begin{tabular}{|c|c|c|c|c|c|c|c|c|}
\hline \multirow[t]{3}{*}{ Content of Question } & \multicolumn{6}{|c|}{ Segment } & \multirow[t]{3}{*}{$F^{2}$} & \multirow[t]{3}{*}{$C^{3}$} \\
\hline & \multicolumn{2}{|c|}{ Decision } & \multicolumn{2}{|c|}{ Support } & \multicolumn{2}{|c|}{ Cost } & & \\
\hline & $M$ & $(S D)$ & $M$ & $(S D)$ & $M$ & $(S D)$ & & \\
\hline Severity of Bullying at Our School & 3.3 & $(1.2)$ & 3.4 & $(1.1)$ & 3.2 & $(1.1)$ & 2.0 & \\
\hline My Responsibility for Prevention & 4.2 & $(0.9)$ & 4.1 & $(1.0)$ & 3.9 & $(1.0)$ & $4.5^{*}$ & $\mathrm{D}, \mathrm{S}>\mathrm{C}$ \\
\hline School's Responsibility for Prevention & 4.5 & $(0.8)$ & 4.6 & $(0.8)$ & 4.4 & $(0.8)$ & 2.0 & \\
\hline Parent's Responsibility for Prevention & 2.8 & $(1.1)$ & 2.7 & $(1.2)$ & 3.2 & $(1.1)$ & $8.5^{* * *}$ & $\mathrm{C}>\mathrm{D}, \mathrm{S}$ \\
\hline Anticipated Benefits of Prevention & 4.1 & $(0.8)$ & 4.1 & $(0.8)$ & 3.8 & $(0.9)$ & $5.3 * *$ & $\mathrm{D}, \mathrm{S}>\mathrm{C}$ \\
\hline Decision Control & 3.7 & $(0.9)$ & 3.6 & $(1.0)$ & 3.5 & $(1.0)$ & 3.0 & $\mathrm{D}>\mathrm{C}$ \\
\hline Barriers to Implementation & 2.6 & $(1.0)$ & 2.5 & $(1.0)$ & 3.0 & $(1.1)$ & $14.2 * * *$ & $\mathrm{C}>\mathrm{D}, \mathrm{S}$ \\
\hline Stakeholder Support & 4.1 & $(0.7)$ & 4.0 & $(0.8)$ & 3.9 & $(0.9)$ & $3.4^{*}$ & $\mathrm{D}>\mathrm{C}$ \\
\hline Consensus Among Staff & 3.3 & $(0.5)$ & 3.3 & $(0.6)$ & 3.3 & $(0.6)$ & 0.3 & \\
\hline Student Morale & 4.1 & $(0.8)$ & 4.0 & $(0.8)$ & 4.1 & $(0.8)$ & $5.4 * *$ & $\mathrm{D}>\mathrm{S}$ \\
\hline Staff Morale & 4.1 & $(0.9)$ & 4.0 & $(0.9)$ & 4.2 & $(0.9)$ & 2.4 & \\
\hline Intent to Implement & 4.3 & $(0.7)$ & 4.4 & $(0.6)$ & 4.1 & $(0.7)$ & $8.1^{* * *}$ & $\mathrm{~S}, \mathrm{D}>\mathrm{C}$ \\
\hline
\end{tabular}


division, experience, or participation in prevention programs (Table 1).

Estimates of the severity of bullying in the schools of the three segments did not differ (Table 2). The Cost Sensitive segment was less likely to agree that it was their responsibility to prevent bullying and more likely to agree that prevention was the responsibility of parents. In comparison to the Decision and Support Sensitive segments, Cost Sensitive educators anticipated more barriers to bullying prevention, expected fewer benefits, and were less likely to become involved in bullying prevention programs. They expected less stakeholder support than did the Decision Sensitive segment. The Decision Sensitive segment reported higher student morale than Support Sensitive educators.

Between-segments MANOVAs across importance scores, $F(40,2308)=41.80, p<0.001$, and utility values, $F(80$, $2268)=5,734.18, p<0.001$, yielded statistically significant segment effects. Univariate ANOVAs and post-hoc Dunnet's $C$ comparisons are presented in Tables 3 and 4. The importance scores and utility values for the attributes discussed below are ranked in order of their importance to the Decision Sensitive segment.

Universal Versus Indicated Programming Importance scores (Table 3) show this attribute exerted more influence on the choices of the Decision and Support Ssensitive segments than those of the Cost Sensitive segment. Utility values (Table 4) showed that, although each segment preferred programs focusing on all students rather than those who bully or are victimized, the Decision and Support Sensitive segments showed a stronger preference than the Cost Sensitive segment for universal programs.

Sustainability Sustainability influenced the choices of the Decision Sensitive segment more than those of the Support

Table 3 Importance Scores for the Decision Sensitive, Support Sensitive, and Cost Sensitive Segments

\begin{tabular}{|c|c|c|c|c|c|c|c|c|c|c|c|c|}
\hline \multirow[t]{3}{*}{ Attribute } & \multicolumn{9}{|c|}{ Segment } & \multirow[t]{3}{*}{$F^{2}$} & \multirow[t]{3}{*}{$C^{3}$} & \multirow[t]{3}{*}{$E t a^{2}$} \\
\hline & \multicolumn{3}{|c|}{ Decision } & \multicolumn{3}{|c|}{ Support } & \multicolumn{3}{|c|}{ Cost } & & & \\
\hline & $R^{1}$ & $M$ & $(S D)$ & $R$ & $M$ & $(S D)$ & $R$ & $M$ & $(S D)$ & & & \\
\hline Universal vs Indicated Programming & 1 & 9.0 & $(1.0)$ & 1 & 9.0 & $(1.0)$ & 2 & 7.3 & $(2.2)$ & $76.6^{* * *}$ & $\mathrm{D}, \mathrm{S}>\mathrm{C}$ & 0.18 \\
\hline Sustainability & 2 & 8.1 & $(1.0)$ & 3 & 7.0 & $(1.4)$ & 3 & 7.3 & $(2.2)$ & $55.2 * * *$ & $\mathrm{D}>\mathrm{S}, \mathrm{C}$ & 0.12 \\
\hline Student Support & 3 & 7.7 & $(1.1)$ & 2 & 7.4 & $(1.3)$ & 6 & 5.7 & $(2.1)$ & $93.0 * * *$ & $\mathrm{D}>\mathrm{S}>\mathrm{C}$ & 0.18 \\
\hline Supporting Evidence & 4 & 6.6 & $(1.1)$ & 4 & 6.7 & (1.3) & 4 & 6.5 & $(2.0)$ & 0.8 & & 0.00 \\
\hline Cultural Sensitivity & 5 & 6.4 & (1.6) & 6 & 6.4 & $(1.8)$ & 5 & 6.1 & (2.4) & 1.6 & & 0.00 \\
\hline Staff Support & 6 & 5.9 & $(1.0)$ & 8 & 6.0 & $(1.2)$ & 15 & 4.1 & $(1.5)$ & $151.3 * * *$ & $\mathrm{D}, \mathrm{S}>\mathrm{C}$ & 0.24 \\
\hline Ongoing Support & 7 & 5.8 & $(1.1)$ & 5 & 6.5 & $(1.0)$ & 9 & 5.0 & (1.9) & $73.8 * * *$ & $\mathrm{~S}>\mathrm{D}>\mathrm{C}$ & 0.16 \\
\hline Parental Involvement & 8 & 5.7 & $(1.5)$ & 7 & 6.2 & $(1.7)$ & 10 & 5.0 & (2.3) & $30.0 * * *$ & $\mathrm{~S}>\mathrm{D}>\mathrm{C}$ & 0.06 \\
\hline Teaching Process & 9 & 5.2 & (1.1) & 9 & 5.7 & $(1.0)$ & 12 & 4.4 & (1.7) & $66.4 * * *$ & $\mathrm{D}>\mathrm{S}>\mathrm{C}$ & 0.13 \\
\hline Staff Involvement & 10 & 4.9 & $(1.1)$ & 10 & 5.3 & $(0.9)$ & 18 & 3.4 & (1.4) & $173.1 * * *$ & $\mathrm{~S}>\mathrm{D}>\mathrm{C}$ & 0.27 \\
\hline Parent Support & 11 & 4.7 & $(1.1)$ & 12 & 4.6 & (1.3) & 19 & 3.3 & $(1.5)$ & $74.6^{* * *}$ & $\mathrm{D}, \mathrm{S}>\mathrm{C}$ & 0.12 \\
\hline Teacher Training Materials \& Process & 12 & 4.1 & $(1.0)$ & 11 & 4.6 & $(1.1)$ & 11 & 4.5 & $(1.7)$ & $19.8 * * *$ & $\mathrm{~S}, \mathrm{C}>\mathrm{D}$ & 0.04 \\
\hline Teacher Time per Week & 12 & 4.1 & $(1.9)$ & 17 & 3.1 & $(1.7)$ & 1 & 7.6 & $(2.7)$ & $268.3 * * *$ & $\mathrm{C}>\mathrm{D}>\mathrm{S}$ & 0.38 \\
\hline Program Cost & 12 & 4.1 & $(1.2)$ & 15 & 3.3 & $(1.3)$ & 7 & 5.7 & $(2.2)$ & $136.5 * * *$ & $\mathrm{C}>\mathrm{D}>\mathrm{S}$ & 0.25 \\
\hline Links to Curriculum & 12 & 4.1 & $(1.5)$ & 13 & 4.1 & $(1.6)$ & 13 & 4.4 & $(2.0)$ & 2.2 & & 0.00 \\
\hline Program Location & 16 & 3.8 & $(1.6)$ & 14 & 3.8 & (1.6) & 8 & 5.1 & (2.4) & $30.9 * * *$ & $\mathrm{C}>\mathrm{D}, \mathrm{S}$ & 0.06 \\
\hline Decision Control & 17 & 3.5 & $(2.0)$ & 18 & 3.0 & $(1.7)$ & 14 & 4.2 & (2.6) & $26.9 * * *$ & $\mathrm{C}>\mathrm{D}>\mathrm{S}$ & 0.06 \\
\hline Divisional Breadth & 18 & 2.4 & $(1.3)$ & 16 & 3.2 & $(1.5)$ & 16 & 3.7 & (1.9) & $46.4 * * *$ & $\mathrm{C}>\mathrm{D}>\mathrm{S}$ & 0.08 \\
\hline Program Goals & 19 & 2.3 & $(1.2)$ & 19 & 2.6 & $(1.2)$ & 17 & 3.5 & (1.9) & $31.4 * * *$ & $\mathrm{C}>\mathrm{S}>\mathrm{D}$ & 0.07 \\
\hline Staff Training Time & 20 & 1.6 & $(1.1)$ & 20 & 1.4 & $(0.8)$ & 20 & 3.3 & $(1.7)$ & $121.1 * * *$ & $\mathrm{C}>\mathrm{D}>\mathrm{S}$ & 0.24 \\
\hline
\end{tabular}

${ }^{1}$ Relative rank of importance scores within each segment. Ranked according to importance to Decision Sensitive segment

${ }^{2}$ Brown-Forsythe F

${ }^{3}$ Dunnett's C

${ }^{*} p<0.05$

$* * p<0.01$

$* * * p<0.001$ 


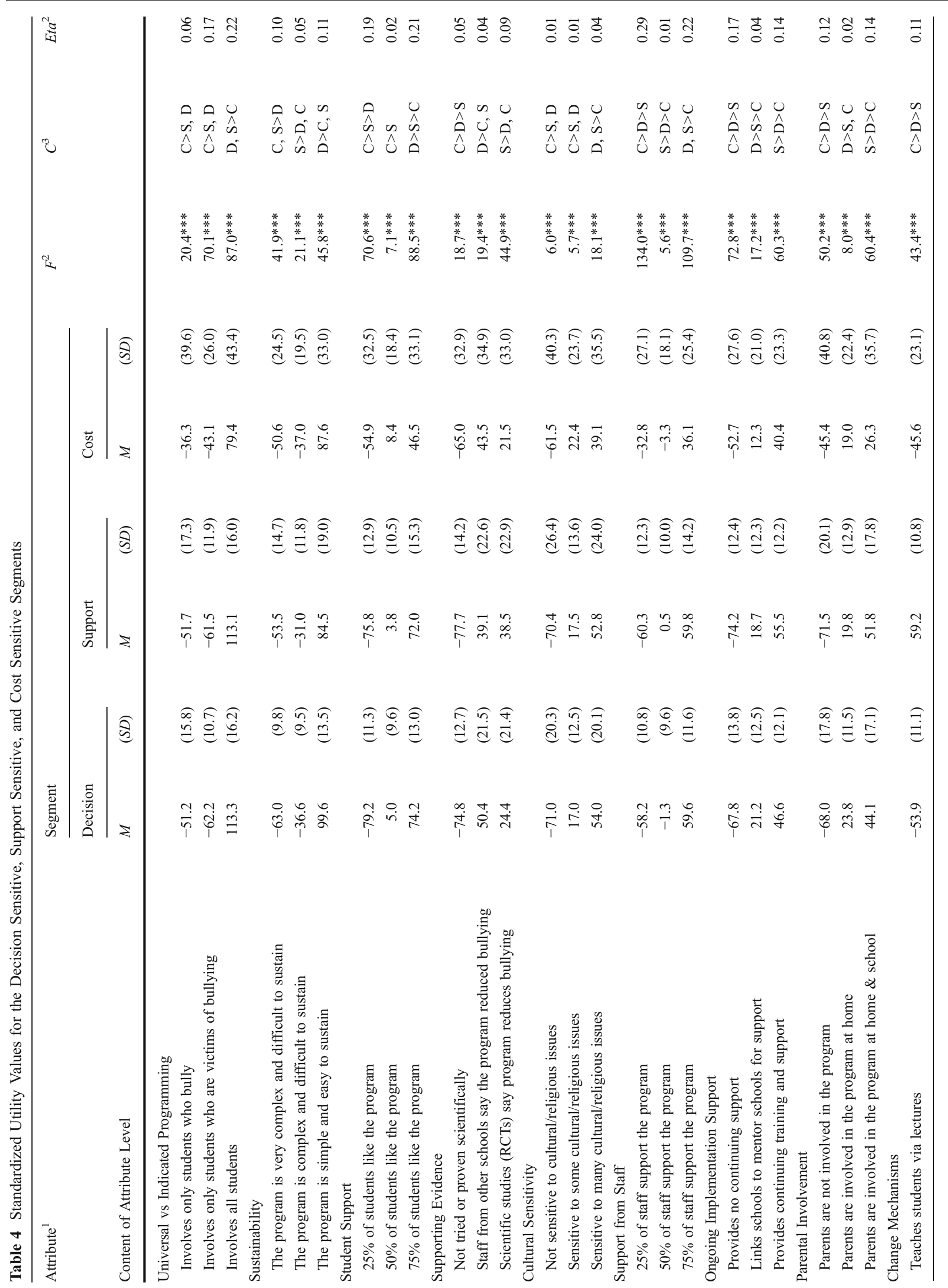




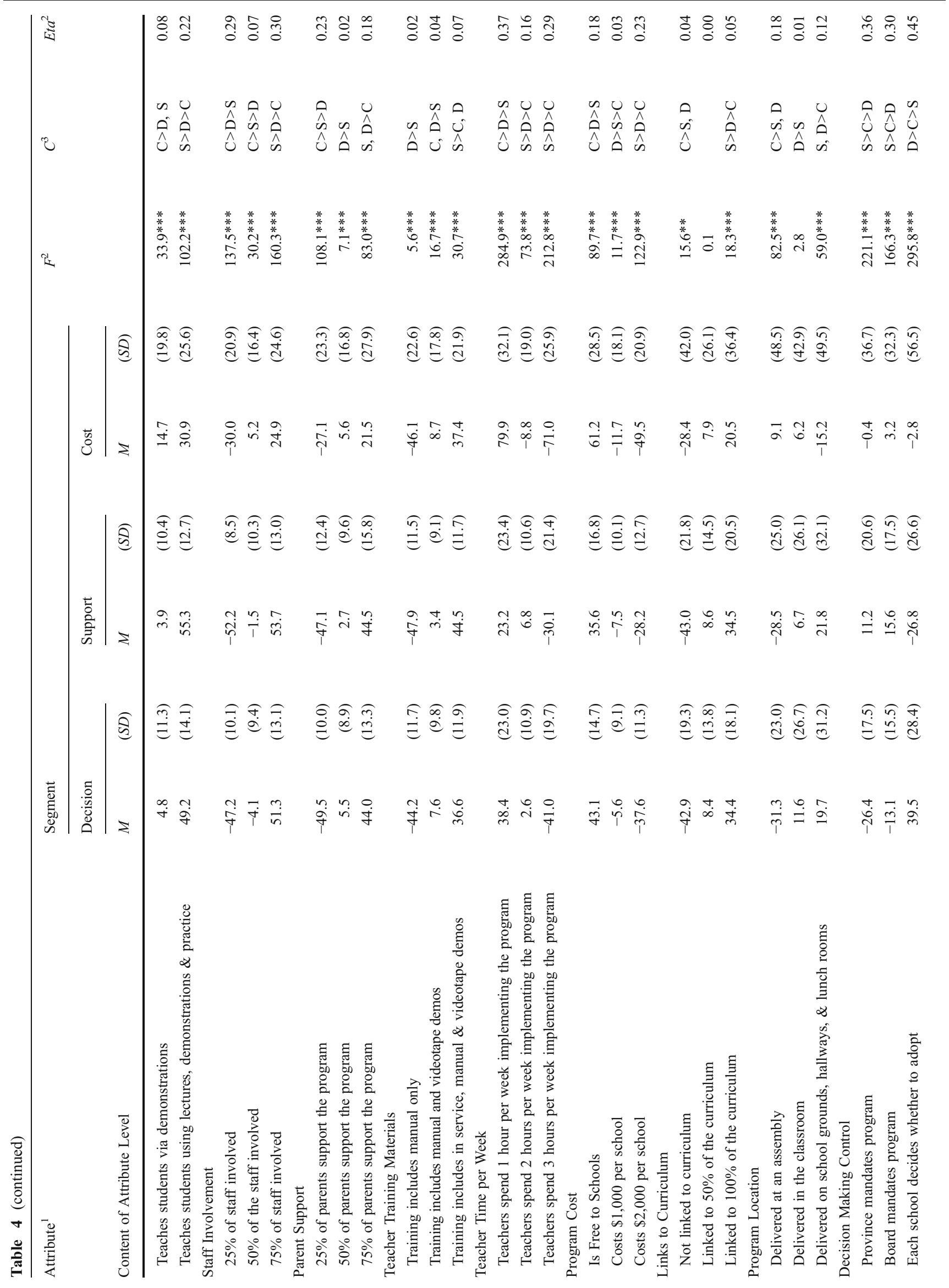




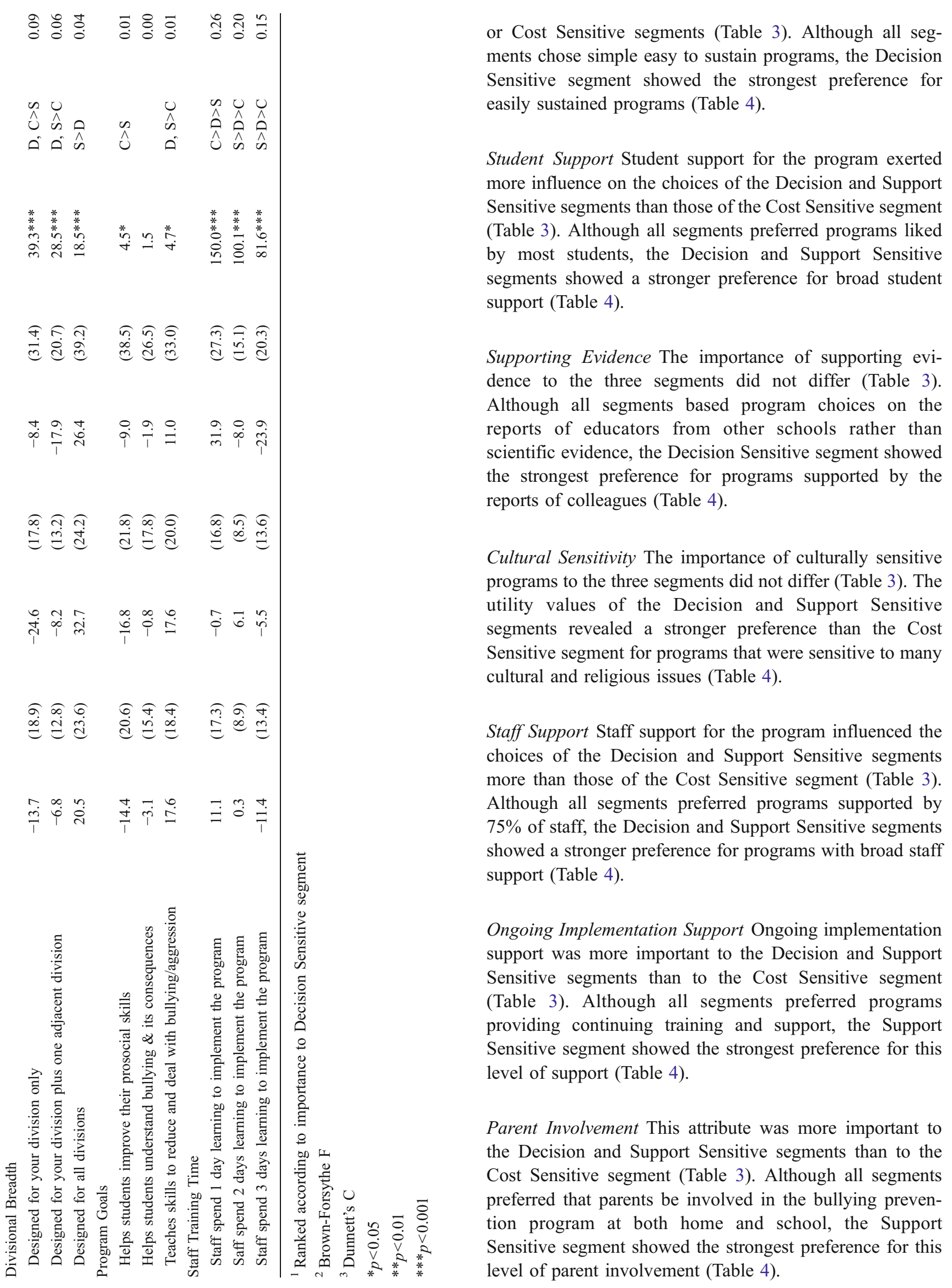


Teaching Process This attribute was more important to the Support and Decision Sensitive segments than to the Cost Sensitive segment (Table 3). Although all segments preferred programs teaching students via a combination of lectures, demonstrations, and practice, the Support Sensitive segment showed a stronger preference for this comprehensive approach.

Staff Involvement Staff involvement was more important to the Support and Decision Sensitive segments than to the Cost Sensitive segment (Table 3). All segments preferred maximum (75\%) staff involvement. The Support Sensitive segment showed a stronger preference for maximum staff involvement than the Decision Sensitive segment who showed a stronger preference for this level than did the Cost Sensitive segment (Table 4).

Parent Support Parental support for the program was most important to the Decision and Support Sensitive segments (Table 3). Although all segments preferred maximum parental support, Decision and Support Sensitive educators showed a significantly stronger preference for maximum parental support than did the Cost Sensitive segment (Table 4).

Teacher Training Materials and Process This attribute was more important to the Support and Cost Sensitive segments than to the Decision Sensitive segment (Table 3). All segments preferred programs including in-service training, manuals, and video demonstrations (Table 4). The Support Sensitive segment showed a stronger preference for comprehensive training materials than did the Decision and Cost Sensitive segments.

Teacher Time Per Week Implementation time demands influenced the Cost Sensitive segment's choices more than the Decision and Support Sensitive segments (Table 3). This was the most important attribute to the Cost Sensitive segment while ranking $12^{\text {th }}$ for the Decision Sensitive segment and $17^{\text {th }}$ for the Support Sensitive segment. Although all segments preferred programs requiring only $1 \mathrm{~h}$ per week (Table 4), the Cost Sensitive segment showed the strongest preference for minimal time demands.

Program Costs Program costs influenced the choices of the Cost Sensitive segment more than those of the Decision and Support Sensitive segments (Table 3). Although all segments preferred programs provided at no cost to schools (Table 4), the Cost Sensitive segment showed the strongest preference for free programs.

Curriculum Links The importance of the program's links to the government curriculum did not differ (Table 3). All segments preferred stronger curriculum links (Table 4). In comparison to Cost Sensitive educators, the Support and Decision Sensitive segments showed stronger preferences for $100 \%$ curriculum links.

Location of the Program The program's location was more important to the Cost Sensitive segment than to the Decision or Support Sensitive segments (Table 3). Cost Sensitive educators preferred conducting prevention programs at assemblies. Decision and Support Sensitive educators, in contrast, preferred programs delivered on playgrounds, in hallways, and in lunch rooms (Table 4).

Decision Control The program selection process was more important to the Cost Sensitive segment than to the Decision and Support Sensitive segments (Table 3). The Decision Sensitive segment preferred individual schoolbased decisions (Table 4). The Support and Cost Sensitive segments, in contrast, preferred programs mandated by school boards.

Divisional Breadth Divisional breadth was more important to the Cost Sensitive segment than to the Decision or Support Sensitive segments (Table 3). All segments preferred programs designed for all (primary, junior, and secondary) divisions (Table 4). The Support Sensitive segment showed a stronger preference than the Decision Sensitive segment for programs applying to all divisions.

Program Goals Program goals were more important to the Cost Sensitive segment than to the Decision or Support Sensitive segments (Table 3). The Decision and Support Sensitive segments showed stronger preferences than the Cost Sensitive segment for programs teaching skills to reduce and deal with bullying rather than teaching general prosocial skills (Table 4).

Staff Training Time Training time demands influenced the choices of the Cost Sensitive segment more than those of the Decision or Support Sensitive segments (Table 3). Although the Cost and Decision Sensitive segments preferred 1 day of implementation training, the Support Sensitive segment preferred 2 days of implementation training (Table 4).

\section{Randomized First Choice Simulations}

Table 5's simulations predict each segment's response to the two hold-out tasks. With mean absolute errors of 0.8 and 1.0 , the internal validity of our simulations was high (Orme 2006). Next, we modeled each segment's response 
Table 5 Observed and Predicted Share of Preference for Three Bullying Prevention Concepts on Hold-Out Tasks 1 and 2

\begin{tabular}{|c|c|c|c|c|c|c|c|c|c|c|}
\hline & \multicolumn{2}{|l|}{ Concept 1} & \multirow[b]{2}{*}{$(s e)$} & \multicolumn{2}{|l|}{ Concept 2} & \multirow[b]{2}{*}{$(s e)$} & \multicolumn{2}{|l|}{ Concept 3} & \multirow[b]{2}{*}{$(\mathrm{se})$} & \multirow[t]{2}{*}{$\mathrm{mae}^{1}$} \\
\hline & Observed & Predicted & & Observed & Predicted & & Observed & Predicted & & \\
\hline 1 & 2.6 & 1.7 & $(0.3)$ & 95.7 & 96.9 & $(0.4)$ & 1.7 & 1.4 & $(0.3)$ & 0.8 \\
\hline 2 & 2.9 & 1.7 & $(0.3)$ & 95.4 & 96.9 & $(0.4)$ & 1.7 & 1.4 & $(0.3)$ & 1.0 \\
\hline
\end{tabular}

${ }^{1}$ mean absolute error

to five hypothetical universal bullying prevention programs: (1) a simple assembly supported by the experience of educators helping students understand bullying and its consequences, (2) a complex scientifically proven classroom program teaching social skills, (3) a complex scientifically proven program teaching social skills on playgrounds, in hallways, and in lunch rooms, (4) a complex scientifically proven classroom program teaching skills to reduce and respond to bullying, and (5) a complex scientifically proven program teaching skills to reduce and respond to bullying, conducted on playgrounds, in hallways, and in lunch rooms. All other attributes were held constant. Finally, to model cost sensitivity, we simulated each segment's response to increasing program costs (free to \$2000) and training time (1 to 3 days) for the playground and classroom programs.

Rather than teaching social skills, most Decision and Support Sensitive educators preferred programs focusing on skills to reduce and respond to bullying (Table 6). Cost Sensitive educators, in contrast, preferred assemblies helping students understand bullying and its consequences. As program costs and training demands of the four classroom and playground programs increased, the Cost Sensitive segment's preference for assemblies increased $(29.3 \%$ to $58.4 \%)$. Despite increasing program and training time costs, only $15.7 \%$ of the Decision Sensitive segment and $3.9 \%$ of the Support Sensitive segment favored less costly assemblies.

\section{Discussion}

As predicted, there was considerable variation in the relative importance of the attributes studied here. As a number of program adoption models suggest, educators were sensitive to program specific attributes (e.g. a universal school-wide focus), the implementation process, (e.g. ongoing support), and broader contextual influences (e. g. consistency with the government curriculum) (Greenhalgh et al. 2004; Lochman 2003; Ringeisen et al. 2003). As predicted by the TPB, program choices were sensitive to information regarding the effectiveness of bullying prevention (Attitudes), the support of colleagues, students, and parents (Subjective Norms), and attributes of the program and implementation process influencing their ability to conduct these programs successfully (Perceived Behavioral Control) (Armitage and Conner 2001; Perkins et al. 2007). Despite a similar pattern of preferences for many attributes, latent class analysis revealed individual differences in the sensitivity of the Decision, Support, and Cost Sensitive segments to attributes reflecting different components of the TPB (Perkins et al. 2007).

\section{Decision Sensitive Segment}

Decision Sensitive educators (31\%) preferred that individual schools, rather than school districts or governments, select bullying prevention programs. Program attributes

Table 6 Randomized First Choice Simulations Predicting the Percentage of Educators in the Decision Sensitive, Support Sensitive, and Cost Sensitive Segments Who Would Choose Each of Five Hypothetical Bullying Prevention Programs

\begin{tabular}{|c|c|c|c|c|c|c|c|c|}
\hline \multirow[t]{3}{*}{ Prevention Program Option } & \multirow[t]{3}{*}{ Total } & \multirow[t]{3}{*}{$(s e)^{1}$} & \multicolumn{6}{|c|}{ Segment } \\
\hline & & & \multicolumn{2}{|c|}{ Decision } & \multicolumn{2}{|c|}{ Support } & \multicolumn{2}{|l|}{ Cost } \\
\hline & & & $\%$ & $(\mathrm{se})$ & $\%$ & $(\mathrm{se})$ & $\%$ & $(\mathrm{se})$ \\
\hline Understanding Bullying \& Consequences Assembly & 4.9 & $(.6)$ & 1.3 & $(.4)$ & .4 & $(.2)$ & 29.3 & $(3.1)$ \\
\hline Prosocial Skills In Class & 7.9 & $(.6)$ & 7.8 & $(1.1)$ & 6.4 & $(.8)$ & 13.3 & $(2.1)$ \\
\hline Prosocial Skills on Playground & 11.0 & $(.8)$ & 11.1 & $(1.3)$ & 10.9 & $(1.1)$ & 11.2 & $(2.0)$ \\
\hline Skills to Reduce \& Respond to Bullying In Class & 32.7 & $(1.2)$ & 35.6 & $(2.0)$ & 32.2 & $(1.7)$ & 27.4 & $(2.9)$ \\
\hline Skills to Reduce \& Respond to Bullying on Playground & 43.6 & $(1.3)$ & 44.2 & $(2.1)$ & 50.2 & $(1.8)$ & 18.8 & $(2.6)$ \\
\hline
\end{tabular}

\footnotetext{
${ }^{1}$ Standard Error
} 
(e. g. simplicity and sustainability) linked to successful implementation (Greenberg 2004; Rogers 2003) were particularly important to this segment. In comparison to Cost Sensitive educators, the Decision Sensitive segment believed prevention programs were more successful, perceived themselves to have more control over implementation decisions, expected fewer barriers, and anticipated greater support from administrators, colleagues, and parents. As the TPB would suggest, Decision Sensitive educators reported higher scores on the intent to implement bullying prevention scale (Armitage and Conner 2001) and seemed more likely to be the innovators and early adopters who initiate the implementation of new prevention programs (Rogers 2003).

\section{Support Sensitive Segment}

The program choices of Support Sensitive educators (51\%) were sensitive to contextual factors that influence the adoption, implementation, and maintenance of bullying prevention programs (Greenberg et al. 2003; Greenberg 2004; Midthassel 2008; Payne et al. 2006; Ringeisen et al. 2003). Given their organizational responsibilities, it is not surprising that administrators were more likely to be members of this segment. Support Sensitive educators were influenced by the social and organizational norms that the TPB (Armitage and Conner 2001; Perkins et al. 2007) and diffusion of innovation models (Rogers 2003) link to behavior change. Like Decision Sensitive educators, the staff, parent, and student support needed to implement prevention programs successfully influenced this segment's choices more than those of Cost Sensitive educators. Predictably, they showed a stronger preference than Decision and Cost Sensitive educators for programs maximizing staff and parental involvement.

Support Sensitive educators also preferred the contextual integration that encourages adoption (Rogers 2003) and improves outcomes (Elias et al. 2003; Ringeisen et al. 2003). They showed a stronger preference for scientific evidence, preferred that school boards choose bullying prevention programs, and, like their Decision Sensitive colleagues, demonstrated a stronger preference for programs linked closely to the provincial curriculum. In comparison to the Decision Sensitive segment, they responded more favorably to programs extending across the elementary, middle, and secondary divisions.

Although their experience with prevention programs did not differ from that of the Decision and Cost Sensitive Segments, Support Sensitive educators chose to spend twice as much time learning to implement programs and showed a stronger preference for a comprehensive package of in-service training, manuals, video demonstrations, continuing training, and support. Like the Decision Sensi- tive segment, they demonstrated a stronger preference than Cost Sensitive educators for programs combining lectures, demonstrations, and practice exercises to teach bullying prevention skills.

\section{Cost Sensitive Segment}

Cost Sensitive educators (16\%) showed a stronger preference for low cost programs minimizing training and implementation time demands. The time required to conduct programs influenced the choices of Cost Sensitive educators more than any other attribute. They were less likely to agree that prevention was their responsibility and more likely to agree that prevention was the responsibility of parents. Although most (62.4\%) had participated in the implementation of prevention programs, they expected fewer benefits, were less likely to agree that there was adequate time and space in the curriculum for bullying prevention, and felt they were less likely to be supported by stakeholders. As the TPB would predict, Cost Sensitive educators were less intent on participating in bullying prevention program implementation (Armitage and Conner 2001; Perkins et al. 2007). Simulations showed that, in contrast to the Decision and Support Sensitive segments who preferred teaching prevention skills on playgrounds, in hallways, and in lunchrooms where most bullying occurs (Craig et al. 2000), Cost Sensitive educators preferred a less demanding, non-evidence-based program teaching social skills at an assembly.

\section{Implications}

Educators based program choices on the reports of their colleagues rather than scientific evidence, an observation consistent with diffusion of innovation models (Rogers 2003). To ensure the adoption of effective programs, the choices available to individual schools could be restricted to an approved list of evidence-based bullying prevention approaches (Greenberg 2004). Given the sensitivity of participants to the experiences of their colleagues, testimonials from educators who have implemented these programs could be included in materials describing each option. Because a favorable student response was important, dissemination materials should also include feedback from students regarding key program attributes. Investigators conducting trials of bullying prevention programs could anticipate the information needed to support the dissemination of effective programs by adopting a mixed methods approach capturing both quantitative ratings and narrative comments regarding program attributes that are important to each segment (Barbour 1999; Coast 1999).

An approach to dissemination including a menu of evidence-based options coupled with school-based adoption 
decisions has several advantages. First, this approach addresses the Decision Sensitive segment's preference for local decision control and the preference of Support and Cost Sensitive educators for centrally mandated programs. Second, local decisions are more likely to yield programs consistent with the preferences (utilities) of the educators in an individual school. Third, organizational research suggests that the opportunity to participate in workplace decisions increases satisfaction with decision outcomes (Shapiro and Brett 2005) and encourages participation in the implementation of organizational innovations (Cunningham et al. 2002; Elias et al. 2003). Given an opportunity to contribute to program adoption decisions, for example, Cost Sensitive educators may be more likely to support a bullying prevention program exceeding their training and implementation cost thresholds. In combination, these factors may account for the finding that local program selection processes improve prevention program implementation (Payne et al. 2006).

Our results suggest that, to ensure successful dissemination, each segment's preferences must inform the design and implementation of bullying prevention programs (Schoenwald and Hoagwood 2001). As innovators and early adopters (Rogers 2003), for example, Decision Sensitive educators play an important role in the decision to introduce bullying prevention programs. Program design and selection must also consider the Support Sensitive segment's preference for contextual integration, comprehensive training, stakeholder involvement, and long-term support. Although these attributes may increase implementation time costs, they are critical to the success of schoolbased prevention programs (Elias et al. 2003; Ringeisen et al. 2003) and consistent with evidence that comprehensive long-term programs yield more enduring prevention effects (Greenberg et al. 2003). Because Decision and Support Sensitive educators were more sensitive to variations in the support of their colleagues, they may be unduly influenced by the reluctance of Cost Sensitive educators to support programs with higher training and implementation costs. The need to accommodate the Cost Sensitive segment's cost reduction preferences is supported by evidence that financial concerns often limit the sustainability of potentially effective prevention programs (Elias et al. 2003).

Rather than conducting programs in their classrooms, most educators preferred teaching bullying prevention skills where bullying often occurs (e.g. playgrounds, hallways, and lunchrooms) (Craig et al. 2000). Simulations suggested most Decision and Support Sensitive educators would choose a program teaching bullying prevention skills rather than an approach focusing on more general prosocial skills. This choice is supported by systematic reviews suggesting that, although programs focusing on prosocial skills improve social competence, their impact on bullying is less clear (Merrell and Isava 2008; Vreeman and Carroll 2007).
Limitations

Given their desire to limit time demands, Cost Sensitive educators may have been less likely to enroll in this study. Accordingly, our analyses might underestimate the percentage of participants in that segment. Second, the response of participants to identical hold-out choice tasks suggests that informant reliability was high. Hold-out task predictions, moreover, suggest the internal validity of our simulations was high. Nonetheless, failing to include important contextual factors (Payne et al. 2006; Ringeisen et al. 2003), could reduce the accuracy of our models (Orme 2006). Finally, our findings reflect choices at the adoption stage of the program implementation process (Louviere et al. 2007). The TPB predicts that preferences may shift if bullying prevention outcomes fall short of expectations, educators encounter unexpected barriers, or stakeholders reduce their support for the program (Armitage and Conner 2001).

\section{Summary}

In the absence of a prevention program selection process restricting choices to evidence-based options, the preference of educators for anecdotal reports may undermine efforts to reduce bullying. To ensure the evidence-based bullying prevention options available reflect the complex combination of attributes influencing real world adoption decisions, program developers need to collaborate with educators whose preferences represent the differing views of the Decision, Support, and Cost Sensitive segments. Finally, given the sensitivity of educators to stakeholder support, student and parental input during the program design phase will contribute to the support needed for adoption, implementation, and long term maintenance.

\section{References}

Allenby, G. M., Arora, N., \& Gintner, J. L. (1995). Incorporating prior knowledge into the analysis of conjoint studies. JMR, Journal of Marketing Research, 32, 152-162. doi:10.2307/3152044.

Armitage, C. J., \& Conner, M. (2001). Efficacy of the theory of planned behaviour: a meta-analytic review. The British Journal of Social Psychology, 40(4), 471-499. doi:10.1348/014466601164939.

Arseneault, L., Walsh, E., Trzesniewski, K., Newcombe, R., Caspi, A., \& Moffitt, T. E. (2006). Bullying victimization uniquely contributes to adjustment problems in young children: a nationally representative cohort study. Pediatrics, 118(1), 130 138. doi:10.1542/peds.2005-2388.

Barbour, R. S. (1999). The case for combining qualitative and quantitative approaches in health services research. Journal of Health Services Research \& Policy, 4(1), 39-43.

Caruso, E. M., Rahnev, D. A., \& Banaji, M. R. (2009). Using conjoint analysis to detect discrimination: revealing covert preferences from overt choices. Social Cognition, 27(1), 128-137. doi:10.1521/ soco.2009.27.1.128. 
Coast, J. (1999). The appropriate uses of qualitative methods in health economics. Health Economics, 8(4), 345-353. doi:10.1002/(SICI) 1099-1050(199906)8:4<345::AID-HEC432>3.0.CO;2-Q.

Craig, W. M., Pepler, D., \& Atlas, R. (2000). Observations of bullying in the playground and in the classroom. School Psychology International, 21(1), 22-36. doi:10.1177/0143034300211002.

Cunningham, C. E., Deal, K., Rimas, H., Buchanan, D. H., Gold, M., Sdao-Jarvie, K., et al. (2008). Modeling the information preferences of parents of children with mental health problems: a discrete choice conjoint experiment. Journal of Abnormal Child Psychology, 7(36), 1128-1138.

Cunningham, C. E., Vaillancourt, T., Cunningham, L. J., \& Short, K. (2009). The bullying prevention attitudes scale. Unpublished manuscript.

Cunningham, C. E., Cunningham, L. J., Martorelli, V., Tran, A., Young, J., \& Zacharias, R. (1998). The effects of primary division, student-mediated conflict resolution programs on playground aggression. Journal of Child Psychology and Psychiatry, and Allied Disciplines, 39(5), 653-662. doi:10.1017/ S0021963098002558.

Cunningham, C. E., Woodward, C. A., Shannon, H. S., MacIntosh, J., Lendrum, B., Rosenbloom, D., et al. (2002). Readiness for organizational change: a longitudinal study of workplace, psychological and behavioural correlates. Journal of Occupational and Organizational Psychology, 75(4), 377-392. doi:10.1348/096317902321119637.

DeSarbo, W. S., Ramaswamy, V., \& Cohen, S. H. (1995). Market segmentation with choice-based conjoint analysis. Marketing Letters, 6(2), 137-147. doi:10.1007/BF00994929.

Elias, M. J., Zins, J. E., Graczyk, P. A., \& Weissberg, R. P. (2003). Implementation, sustainability, and scaling up of socialemotional and academic innovations in public schools. School Psychology Review, 32(3), 303-320.

Fagan, A. A., \& Mihalic, S. (2003). Strategies for enhancing the adoption of school-based prevention programs: lessons learned from the blueprints for violence prevention replications of the life skills training program. Journal of Community Psychology, 31 (3), 235-253. doi:10.1002/jcop.10045.

Fekkes, M., Pijpers, F. I., \& Verloove-Vanhorick, S. P. (2006). Effects of antibullying school program on bullying and health complaints. Archives of Pediatrics \& Adolescent Medicine, 160(6), 638-644. doi:10.1001/archpedi.160.6.638.

Frey, K. S., Hirschstein, M. K., Snell, J. L., Edstrom, L. V., MacKenzie, E. P., \& Broderick, C. J. (2005). Reducing playground bullying and supporting beliefs: an experimental trial of the steps to respect program. Developmental Psychology, 41 (3), 479-490. doi:10.1037/0012-1649.41.3.479.

Gamage, J., \& Weerahandi, S. (1998). Size performance of some tests in one-way anova. Communications in Statistics Simulation and Computation, 27(3), 625-640. doi:10.1080/03610919808813500.

Greenberg, M. T. (2004). Current and future challenges in schoolbased prevention: the researcher perspective. Prevention Science, 5(1), 5-13. doi:10.1023/B:PREV.0000013976.84939.55.

Greenberg, M. T., Weissberg, R. P., O'Brien, M. U., Zins, J. E., Fredericks, L., Resnik, H., et al. (2003). Enhancing school-based prevention and youth development through coordinated social, emotional, and academic learning. The American Psychologist, 58(6-7), 466-474. doi:10.1037/0003-066X.58.6-7.466.

Greenhalgh, T., Robert, G., Macfarlane, F., Bate, P., \& Kyriakidou, O. (2004). Diffusion of innovations in service organizations: systematic review and recommendations. The Milbank Quarterly, 82(4), 581-629. doi:10.1111/j.0887378X.2004.00325.x.

Gregory, A., Henry, D. B., \& Schoeny, M. E. (2007). School climate and implementation of a preventive intervention. American Journal of Community Psychology, 40(3-4), 250-260. doi:10.1007/s10464-007-9142-z.
Gustafsson, A., Herrmann, A., \& Huber, F. (2007). Conjoint analysis as an instrument of market research practice. In A. Gustafsson, A. Herrmann \& F. Huber (Eds.), Conjoint measurement (pp. 334). Berlin, Germany: Springer.

Hensher, D. A., Rose, J. M., \& Greene, W. H. (2005). Applied choice analysis A primer. New York-U.S.A.: Cambridge University Press.

Hoagwood, K., \& Johnson, J. (2003). School psychology: a public health framework I. From evidence-based practices to evidencebased policies. Journal of School Psychology, 41(1), 3-21. doi:10.1016/S0022-4405(02)00141-3.

Huber, J., Orme, B., \& Miller, R. (2007). Dealing with product similarity in conjoint simulations. In A. Gustafsson, A. Herrmann \& F. Huber (Eds.), Conjoint measurement: methods and applications (4th ed., pp. 347-362). New York: Springer.

Kallestad, J. H. (2003). Predicting teachers' and schools' implementation of the olweus bullying prevention program: a multilevel study. Prevention \& Treatment, 6, 3-21.

Kim, Y. S., Leventhal, B. L., Koh, Y. J., Hubbard, A., \& Boyce, W. T. (2006). School bullying and youth violence: causes or consequences of psychopathologic behavior? Archives of General Psychiatry, 63(9), 1035-1041. doi:10.1001/archpsyc.63.9.1035.

Lenk, P. J., DeSarbo, W. S., Green, P. E., \& Young, M. R. (1996). Hierarchical bayes conjoint analysis: recovery of partworth heterogeneity from reduced experimental designs. Marketing Science, 15(2), 173-192. doi:10.1287/mksc.15.2.173.

Lochman, J. E. (2003). Commentary: school contextual influences on the dissemination of interventions. School Psychology Review, 32 (2), 174-178.

Louviere, J., Hensher, D., \& Swait, J. (2007). Conjoint preference elicitation methods in the broader context of random utility theory preference elicitation methods. In A. Gustafsson, A. Herrmann \& F. Huber (Eds.), Conjoint measurement-methods and applications (4th ed., pp. 167-197). New York: Springer.

Luce, R. D., \& Tukey, J. W. (1964). Simultaneous conjoint measurement: a new type of fundamental measurement. Journal of Mathematical Psychology, 1(1), 1-27. doi:10.1016/0022-2496 (64)90015-X.

Merrell, K. W., \& Isava, D. M. (2008). How effective are school bullying intervention programs? School Psychology Quarterly, 23(1), 26-42. doi:10.1037/1045-3830.23.1.26.

Midthassel, U. V. (2008). Is the sustainability of reduction in bullying related to follow-up procedures? Educational Psychology, 28(1), 1-13. doi:10.1080/01443410701449278.

Mytton, J., DiGuiseppi, C., Gough, D., Taylor, R., \& Logan, S. (2006). School-based secondary prevention programmes for preventing violence. Cochrane Database of Systematic Reviews (Online), 3. doi:10.1002/14651858.CD004606.pub2.

Olweus, D. (1994). Bullying at school: basic facts and effects of a school based intervention program. Journal of Child Psychology and Psychiatry, and Allied Disciplines, 35(7), 1171-1190. doi:10.1111/j.1469-7610.1994.tb01229.x.

Orme, B. K. (2006). Getting started with conjoint analysis: strategies for product design and pricing research. Madison: Research Publishers.

Patterson, M., \& Chrzan, K. (2004). Partial profile discrete choice: what's the optimal number of attributes? (pp. 173-185). San Antonio, TX: 2003 Sawtooth Software Conference Proceedings.

Payne, A. A., Gottfredson, D. C., \& Gottfredson, G. D. (2006). School predictors of the intensity of implementation of school-based prevention programs: results from a national study. Prevention Science, 7(2), 225-237. doi:10.1007/s11121-006-0029-2.

Perkins, M. B., Jensen, P. S., Jaccard, J., Gollwitzer, P., Oettingen, G., Pappadopulos, E., et al. (2007). Applying theory-driven approaches to understanding and modifying clinicians' behavior: what do we know? Psychiatric Services (Washington, D.C.), 58 (3), 342-348. doi:10.1176/appi.ps.58.3.342. 
Phillips, K. A., Johnson, F. R., \& Maddala, T. (2002). Measuring what people value: a comparison of "attitude" and "preference" surveys. Health Services Research, 37(6), 1659-1679. doi:10.1111/1475-6773.01116.

Ramaswamy, V., \& Cohen, S. H. (2007). Latent class models for conjoint analysis. In A. Gustafsson, A. Herrmanm \& F. Huber (Eds.), Conjoint measurement methods and applications (4th ed., pp. 295-320). Heidelberg: Springer.

Ringeisen, H., Henderson, K., \& Hoagwood, K. (2003). Context matters: schools and the "research to practice gap" in children's mental health. School Psychology Review, 32(2), 153-169.

Rogers, E. M. (2003). Diffusion of innovations (5th ed.). New York: Free.

Rones, M., \& Hoagwood, K. (2000). School-based mental health services: a research review. Clinical Child and Family Psychology Review, 3(4), 223-241. doi:10.1023/A:1026425104386.

Ryan, M., Gerard, K., \& Amaya-Amaya, M. (2007). Using discrete choice experiments to value health and health care. Netherlands: Springer.

Ryan, M., Scott, D. A., Reeves, C., Bate, A., van Teijlingen, E. R., Russell, E. M., et al. (2001). Eliciting public preferences for healthcare: a systematic review of techniques. Health Technology Assessment, 5(5), 1-186.

Sawtooth Software Inc. (2004a). The CBC/HB system for hierarchical bayes estimation version 4.0 technical paper. Sawtooth Software Technical Paper Series. Retrieved from http://www.sawtoothsoftware.com/ download/techpap/hbtech.pdf

Sawtooth Software Inc. (2004b). The CBC latent class technical paper (version 3). Sawtooth Software Technical Paper Series. Retrieved from http://www.sawtoothsoftware.com/download/techpap/ lctech.pdf
Schoenwald, S. K., \& Hoagwood, K. (2001). Effectiveness, transportability, and dissemination of interventions: what matters when? Psychiatric Services (Washington, D.C.), 52(9), 1190. doi:10.1176/appi.ps.52.9.1190.

Shah, A. K., \& Oppenheimer, D. M. (2008). Heuristics made easy: an effort-reduction framework. Psychological Bulletin, 134(2), 207. doi:10.1037/0033-2909.134.2.207.

Shapiro, D., \& Brett, J. (2005). What is the role of control in organizational justice? In J. Greenberg \& J. Colquitt (Eds.), Handbook of organizational justice (pp. 155-178). New Jersey: Lawrence Erlbaum Associates.

Shinn, M. (2003). Understanding implementation of programs in multilevel systems. Prevention \& Treatment, 6(1), 22. doi:10.1037/1522-3736.6.1.622c.

Spoth, R., Greenberg, M., Bierman, K., \& Redmond, C. (2004). PROSPER community-university partnership model for public education systems: capacity-building for evidence-based, competence-building prevention. Prevention Science, 5(1), 3139. doi:10.1023/B:PREV.0000013979.52796.8b.

Spoth, R., \& Redmond, C. (1993). Identifying program preferences through conjoint analysis: illustrative results from a parent sample. American Journal of Health Promotion, 8(2), 124-133.

Vreeman, R. C., \& Carroll, A. E. (2007). A systematic review of school-based interventions to prevent bullying. Archives of Pediatrics \& Adolescent Medicine, 161(1), 78-88. doi:10.1001/ archpedi.161.1.78.

Vriens, M., Wedel, M., \& Wilms, T. (1996). Metric conjoint segmentation methods: a Monte Carlo comparison. JMR, Journal of Marketing Research, 33(1), 73-85. doi:10.2307/3152014. 